\title{
A Study of Math Anxiety in Male and Female Students at BA ISAGO University: Empirical Evidence
}

\author{
Morvyn Ngoni Nyakudya ${ }^{1}$, Unity Nyadzisayi Nyakudya ${ }^{2}$ \\ ${ }^{1}$ BA ISAGO University, Gaborone, Botswana \\ ${ }^{2}$ Botswana Accountancy College, Gaborone, Botswana \\ Email: morvyn.nyakudya@baisago.ac.bw, unityn@bac.ac.bw
}

How to cite this paper: Nyakudya, M. N., \& Nyakudya, U. N. (2020). A Study of Math Anxiety in Male and Female Students at BA ISAGO University: Empirical Evidence. Open Journal of Social Sciences, 8 , 345-358.

https://doi.org/10.4236/jss.2020.810023

Received: August 6, 2020

Accepted: October 26, 2020

Published: October 29, 2020

Copyright $\odot 2020$ by author(s) and Scientific Research Publishing Inc. This work is licensed under the Creative Commons Attribution International License (CC BY 4.0).

http://creativecommons.org/licenses/by/4.0/

\begin{abstract}
This study attempts to investigate whether there is any statistically significant difference in math anxiety for male and female students at BA ISAGO University. To assess the students' feelings towards Mathematics, two short instruments were used. The first questionnaire had fifteen math anxiety constructs. The other instrument captured nine questions based on math anxiety constructs in which students were to respond "yes" or "no" to the questions. The population of the study consisted of all BA ISAGO University students across all programmes from which two samples were taken at different stages. The first sample had 254 while the other one was made up of 232 students. The sampling methods used were mixed: random, convenience and purposive. Descriptive, ANOVA and Chi Square analyses were used. Three sets of results came out clearly in this study. Firstly, using a sample of 254 students, the study concluded that there were statistically significant differences between the means for male and female students in respect of "fearing mathematics", "getting worried with mathematics", "avoiding math in their modules" and "avoiding math all together". In the second test, using a sample of 232 students, the study found that there were statistically significant differences between students who said "yes" and those who indicated "no" to "fearing mathematics", "feeling uneasy", "getting worried", "experience a mind block" and "getting bored" with regards mathematics were rejected. Lastly, using the same sample of 232, it was found that there were no statistically significant differences between students who said "yes" and "no" to "fearing to ask", "liking mathematics modules", "liking mathematics in gener$a l$ ", and "sweating".
\end{abstract}

\section{Keywords}

BA ISAGO University, Math Anxiety, Mathematics 


\section{Introduction}

It appears that the problem of mathematics anxiety continues to dominate the education research arena as efforts are channeled towards controlling, if not to completely eliminate it. Schools and colleges are battling to contain the scourge. Botswana has continued to experience the worst results in mathematics and other subjects over the years [Botswana General Certificate in Secondary Education (BGCSE): 2016, 2017 and 2018]. Despite the fact that the Government of Botswana (GoB) continues to sponsor education as one of its top priority areas, the students have not complemented this effort by producing good results especially in mathematics. There seems to be an ever worrying negative correlation between the effort put by the GoB and the subsequent results obtained by the students.

Cognitive abilities of male and female students in mathematics performance seem to be different. It seems that the problem of Math Anxiety needs to be dealt with at all levels: elementary, intermediate and advanced. Some proponents of this phenomenon have even argued that the problem of Math Anxiety can be found even in the unborn babies while others have advanced that, the problem seems to appear in all facets of human life, including the aged. Mathematics remains one of the core subjects in basic sciences and technology improvement. Sciences and technology improvement form the center piece which holds human advancement to keep improving. Consequently, mathematics education needs to be stepped up so as to hold this center piece afloat in order to unleash the hidden potential talent in humankind in general and students in particular. It is however unfortunate, as observed by Ayotola and Adedeji (2009), that students' performance was below expectations. For many years, the results for secondary school mathematics in Botswana have shown a downward trend with no signs of getting any better (Botswana General Certificate in Secondary Education (BGCSE): 2016, 2017 and 2018). Perhaps mathematics performance is being challenged by a problem called mathematics anxiety (MA) which Keshavarzi and Ahmadi (2013) cite as having a negative effect on mathematics learning, involvement and performance in the subject.

This study focuses on the poor mathematics performance probably as a result of the problem of mathematics anxiety. It attempts to portray the problem in a university setup. Specifically, the study aims to compare the level of mathematics anxiety in male and female students at BA ISAGO University, Gaborone, Botswana. The major objective of this study is to investigate if there is a statistically significant difference in the levels of mathematics anxiety between male and female students at BA ISAGO University. Specifically, the study will attempt to explore the mathematics anxiety phenomenon as it is expounded in literature. Form this literature, the study proceeds to investigate the causes of mathematics anxiety in students as well as to compare the levels of mathematics anxiety based on gender. Lastly, the study will attempt to suggest some ways in which mathematics anxiety, if it exists, may be reduced or may be eradicated. 


\section{Literature Review}

The question "What is mathematics anxiety?" has been paused severally in literature over the years. Mathematics anxiety is a phenomenon that humankind continues to live with. Students feel overwhelmed with numbers and calculations as well as experiencing panic and sweaty palms every time they are faced with a mathematics test or examination. Many BA ISAGO University students have deferred the mathematics modules until the very end of their study, an avoidance syndrome that has become quite prevalent in recent years.

Many authors have attempted to shed light regarding the nature of mathematics anxiety. For instance, Keshavarzi and Ahmadi (2013) stressed that if there was nothing done to curb mathematics anxiety, there would be a reduction in "national human resources in science and technology". Hence, a strong background in mathematics was essential. Other authors, including Murat (2009), have lamented that when learning and teaching mathematics, several constructs come into play. These constructs describe learning difficulties and poor performance in mathematics. The constructs are mathematics anxiety, learning styles, instruction, and lack of self-confidence, teacher beliefs, environment and lack of parental support, and gender that appeared to affect students' mathematics learning abilities.

In studying the same phenomenon among high school male and female students in four districts in Shiraz, Keshavarzi and Ahmadi (2013) used Chiu and Henry's mathematics anxiety scale for children (MASC). The instrument used twenty-two (22) short phrases commonly used to describe mathematics anxiety. The sample was picked using random-cluster sampling. The results showed that there was no statistically significant difference between girls and boys in respect of mathematics anxiety. In other words the males and females were equally affected by the phenomenon.

In a similar study, Yeo, Tan and Lew (2015) investigated mathematics anxiety at a private university in Malaysia using a sample of 214 students conveniently sampled. The study used the Mathematics Anxiety Rating Scale (MARS) with three anxiety levels: low, average and high. The results showed average level of anxiety in male and female and concluded that, there was no significant difference of anxiety among the male and female students of the private University.

Adding more variables, Ayotola and Adedeji (2009) carried out a study to investigate the relationship between gender, age, mental ability, anxiety, math self-efficacy and achievement in math. Multiple regression analysis was used. The results showed that mathematics self-efficacy, gender and anxiety had significant correlations with students' achievement in mathematics.

On their part, Henrich and Lee (2011) describe a person with this anxiety as one who may experience, among others, sweaty palms and increased heartbeat. They also note that it can be found at any stage of growth including in the unborn child. Henrich and Lee (2011) further advance their case by enumerating what may cause mathematics anxiety. One major cause, they note, is a bad teacher of ma- 
thematics coupled with the possible fear of failure on the part of the student leading eventually to mathematics avoidance by the student, a view also expressed by Karimi \& Venkatesan (2009) who found out that, there was a significant difference between boys and girls in mathematics anxiety.

Ayotola \& Adedeji (2009) stated that the mathematics anxiety phenomenon was an endemic that negatively impacted on the teaching and learning of mathematics. In another related submission, they noted that "the mathematically anxious students might be expected to lack skills in understanding the condition of a problem and setting up of the solution".

As far back as Thomas (1998) carried out a study to compare the level of math anxiety between male and female at a Community College. Using a convenience sample of 90 students, four sections of an introductory English class were given a mathematics anxiety rating scale (MARS) and a math avoidance survey. Several hypotheses were analyzed using both standard normal distribution tests and chi-square contingency tables. The results showed that male students had less fear for math than their female counterparts. The study also found that "men and women were equivalent in avoiding taking required math courses". Women avoided majors requiring two or more math courses, significantly more than men.

In another study, Erdogan, Kesici \& Sahin (2011) attempted to determine if "achievement motivation and social comparison were significant predictors of high school students' mathematics anxiety”. Their sample consisted of 166 grade 9 students. Multiple linear regression analysis was used with the predictor variables as students' achievement motivation, and social comparison while the dependent variable was mathematics anxiety. The results showed that "achievement motivation alone, and achievement motivation and social comparison together are significant predictors of high school students' mathematics anxiety".

Hlalele's (2012) study was to explore rural high school learners' experience of mathematics anxiety in academic settings basing their discourse on the fact that mathematics anxiety has negative effects on confidence, motivation and achievement. The sample for this study was 403 in 18 rural schools in the Free State province of South Africa. A questionnaire was used as the main research instrument. The findings revealed learners experienced mathematics anxiety in academic settings.

Due to the strong push in New Zealand to make students comfortable with mathematics, Whyte and Anthony (2012) considered the role of math anxiety and its impact on students' learning practices and outcomes. The literature review they cited identified the possible causes of math anxiety and how teachers might assist in reducing math anxiety in students. Their aim was to improve the math uptake by students while dispelling the myths that are manifest in mathematics anxiety.

Ho et al. (2000) used confirmatory factor analyses while studying math anxiety by "comparing its dimensions, levels, and relationship with mathematics achievement across samples of 6th-grade students from China, Chinese Taipei, 
and the United States". They found that gender by different areas had influence on math anxiety.

Pourmoslemi et al. (2013) focused on gender differences and mathematics anxiety using a sample of 275 (162 women and $113 \mathrm{men}$ ). Three variables were used: mathematics anxiety and gender, and field of study. Using One-way ANOVA and independent-samples t-tests, the results of the study showed that there existed "differences between men and women's evaluation anxiety and no significant difference was observed concerning field of study' as well as a significant correlation between high level anxiety and low academic performance.

Ballado (2014) paints a picture of math anxiety when citing four authors who singularly mentioned the following situations that have a close link to the phenomenon: "the manipulation of numbers and the solving of mathematical problems in a wide variety of ordinary and academic situations", "sudden death", "any situation when one experiences anxiety if confronted with mathematics in any way" and "an irrational phobia, and a rational fear rooted in real experience of failure and inadequacy". These four sentiments, from authors of mathematics anxiety, are a painful reality of the problem that the world would prefer to exist without. The fact that these are realities in society that we all live in is depressing, to say the least. When discussing the foregoing, Ballado was carrying out a study in which they used correlation analysis techniques between the level of mathematics anxiety and the academic achievement of a group of students in the University of Eastern Philippines who were engaged in a Problem Solving course. In the same study, Ballado tested the levels of mathematics anxiety and academic achievement among the male and female respondents. The study found that females had a higher level of mathematics anxiety than their male counterparts pointing to a significant difference in the math anxiety levels of male and female students. The criteria used to test this included tests, homework and the rudiments of mathematics, particularly algebra.

Maloney et al. (2011) grapple the subject of high mathematics-anxious (HMA) and low mathematics-anxious (LMA) in as far as the origin of mathematics anxiety is concerned. In their findings, they noted that, HMA individuals have less precise representations of numerical magnitude than their LMA peers, suggesting that mathematics anxiety is associated with low-level numerical deficits that compromise the development of higher level mathematical skills.

Perhaps the most intriguing observation is displayed in the study in which Murat (2009) investigated 506 pre-service teachers to ascertain the differences in their teaching anxiety. Murat's study extended the math anxiety phenomenon to teachers rather than to students only. The reason why Murat could have conducted this study was to try and investigate the problem in the teachers themselves rather than focusing on the students on their own.

The foregoing discussion exposes the problem of math anxiety so explicitly and indirectly or directly indicates the need to address the problem for the good of humankind. For as long as science and technology are to be advanced further and for as long as the fourth industrial revolution is to take charge, math anxiety 
has to be eradicated, for the power of machinery is to be manifested in the genius of human mind.

\section{Research Methodology}

This study used two short but comprehensive questionnaires that covered fifteen and nine mathematics anxiety constructs respectively. The questionnaires were tested for reliability and content validity using reliability and validity analysis. These two methods are commonly used in studies and various authors (Chowdhury et al., 2007: p. 5; Kuo et al., 2009: p. 1326; Sakthivel \& Raju 2006: p. 918; Hung et al., 2010: p. 430; Zadry \& Yusof 2006: p. 1003) have used it extensively. Zadry \& Yusof (2006: p. 1003) remind us that content validity does not involve numerical manipulation but involves subjective judgement by researchers as they attempt to reach a common understanding involving various research concepts.

The purpose of reliability analysis is to test for internal consistency of the research instrument using the Cronbach's Alpha; an alpha value of 0.8 and above is considered as very reliable. Validity Analysis has three components: content, criterion-related and construct validity. Under content validity, a general consensus is reached among researchers and subjects (Chowdhury, Paul \& Das, 2007: p. 6) that every aspect of the phenomenon under study is covered. Criterion-related validity, also called predictive validity or external validity, is premised on the degree to which the measuring instrument is related to an independent measure of the relevant criterion. Lastly, construct validity measures the extent to which the items in a scale measure the same construct.

\section{Sampling and Sampling Technique}

First, a sample of 254 out of a student population of 2000 was picked. At a later stage, another sample of 232 was picked to answer the "yes" or "no" only questions. The possibility of the two samples overlapping was high as they were drawn from the same population during the same period. The selection of groups of students included those in the Faculties of Commerce, the Built Environment, Arts and Science and Education, Law and Paralegal Studies.

\section{Descriptive Statistics}

\section{Demographics}

Based on a sample of 254, the demographic details based on aged range, gender and mathematics grades for the two hundred and fifty-four respondents in the four Faculties surveyed were summarized as depicted in Table 1.

From Table 1, the following can be seen:

\section{Age Ranges within Faculties}

\section{Law and Paralegal Studies}

The Faculty of Law and Paralegal Studies had the lowest number of respondents (15) within all age groups. This Faculty is by far the smallest of the four faculties that participated in the study.

\section{Built Environment, Arts and Science}

This faculty had the highest contribution towards the sample with 113 respondents taking part in the study. The 20 to 25 age group contributed 81 (32\%) 
Table 1. Demographic details.

\begin{tabular}{|c|c|c|c|c|c|c|c|}
\hline & & \multirow{2}{*}{ Age Range } & \multicolumn{2}{|c|}{ Male } & \multicolumn{2}{|c|}{ Female } & \multirow{2}{*}{ Total \% } \\
\hline & & & $\#$ & $\%$ & $\#$ & $\%$ & \\
\hline \multirow[t]{17}{*}{ Faculty } & Law and Paralegal Studies & $<20$ & 0 & 0.0 & 0 & 0.0 & 0 \\
\hline & & $20-25$ & 8 & 3.1 & 5 & 2.0 & 5 \\
\hline & & $>25$ & 1 & 0.4 & 1 & 0.4 & 1 \\
\hline & Built Environment, Arts and Science & $<20$ & 9 & 3.5 & 19 & 7.5 & 11 \\
\hline & & $20-25$ & 38 & 15.0 & 43 & 16.9 & 32 \\
\hline & & $>25$ & 1 & 0.4 & 3 & 1.2 & 2 \\
\hline & Commerce & $<20$ & 7 & 2.8 & 16 & 6.3 & 9 \\
\hline & & $20-25$ & 15 & 5.9 & 36 & 14.2 & 20 \\
\hline & & $>25$ & 2 & 0.8 & 3 & 1.2 & 2 \\
\hline & Education & $<20$ & 0 & 0.0 & 7 & 2.8 & 3 \\
\hline & & $20-25$ & 3 & 1.2 & 12 & 4.7 & 6 \\
\hline & & $>25$ & 5 & 2.0 & 20 & 7.9 & 10 \\
\hline & Total & & 89 & 35.0 & 165 & 65.0 & 100.00 \\
\hline & High School Maths D and below & & 13 & 5.1 & 36 & 14.2 & 19 \\
\hline & High School Maths $\mathrm{C}$ and above & & 66 & 26.0 & 121 & 47.6 & 74 \\
\hline & Did not supply grade & & 9 & 3.5 & 8 & 3.1 & 7 \\
\hline & Total & & 88 & 34.6 & 165 & 65.0 & 100 \\
\hline
\end{tabular}

respondents.

Commerce

The Faculty of Commerce had 79 respondents participating in the study with the 20 to 25 years age group contributing the most (51\% or $20 \%$ ).

Education

The Faculty of Education had 47 respondents participating with the age group over " 25 years" having the highest number ( $25 \%$ or $10 \%)$. This is probably due to the fact that students in the Education Faculty are quite mature, having left their places of employment to acquire qualification in such degrees as Early Childhood Development.

\section{High School Mathematics Grade}

Nine (9) male and eight (8) female students did not supply the high school grade in mathematics. Students who scored "C" or better (that is "A", "B" or "C") totalled 187 made up of sixty-six (66) males and one hundred and twenty-one (121) females. The number of students who had other grades (that is "D", "E", "F", "G" and "U") was 49 (13 male and 36 female).

\section{Mathematics anxiety constructs}

Mathematics anxiety constructs were identified in literature. These were subjected to the two hundred and fifty-four respondents who expressed their level of agreement and disagreement on each of them. The results are presented using Table 2. 
Table 2. Math anxiety.

\begin{tabular}{lccccc}
\hline & \multicolumn{2}{c}{ Male } & \multicolumn{2}{c}{ Female } & \multirow{2}{*}{ Total \% } \\
\cline { 2 - 5 } & No. & $\%$ & No. & $\%$ & \\
\hline I fear. & 16 & 6.3 & 49 & 19.3 & 26 \\
I feel uneasy. & 24 & 9.4 & 59 & 23.2 & 33 \\
I am afraid to ask questions. & 28 & 11.0 & 68 & 26.8 & 38 \\
I am always worried. & 29 & 11.4 & 80 & 31.5 & 43 \\
I worry when faced with more difficult calculations. & 39 & 15.4 & 105 & 41.3 & 57 \\
I don't want any maths in all my modules. & 19 & 7.5 & 60 & 23.6 & 31 \\
I develop and increased heartbeat. & 18 & 7.1 & 44 & 17.3 & 24 \\
I don't want any maths in all my modules. & 20 & 7.9 & 52 & 20.5 & 28 \\
I am happy that I do not have to calculate anything & 23 & 9.1 & 56 & 22.0 & 31 \\
in all my module(s). & & & & & \\
I'm afraid I won't be able to perform maths & 15 & 5.9 & 40 & 15.7 & 22 \\
calculations ever. & & & & & 28 \\
I do not like maths. & 23 & 9.1 & 47 & 18.5 & 28 \\
I am not comfortable with maths. & 50 & 19.7 & 79 & 31.1 & 51 \\
I develop a mind block. & 27 & 10.6 & 61 & 24.0 & 35 \\
I sweat. & 19 & 7.5 & 36 & 14.2 & 22 \\
I get bored & 7.1 & 40 & 15.7 & 23 \\
\hline
\end{tabular}

From Table 2, some pertinent observations can be made. Respondents who tended to agree on the two statements "I worry when faced with more difficult calculations" and "I am not comfortable with maths" constituted over $50 \%$. This means that over half of the respondents basically agreed on the two.

\section{Inferential Statistics}

An ANOVA was performed and results are shown in Table 3.

In the cases that respondents agreed that they "feared mathematics" ( $p<$ $0.05)$, that they "got worried with difficult questions" $(p<0.01)$, that they "did not want any math in their modules" $(p<0.01)$ and that they would "avoid math at the earliest" $(p<0.05)$, the $p$-value indicates that the Null hypothesis that the means for the two genders are the same is rejected. The alternative hypothesis that the means for males and females are different is not rejected. No statistically significant differences were found in the other statements such as "I sweat", " $I$ get bored" and "I do not like math ever".

Based on the sample of 232, the analysis follows.

\section{Descriptive Statistics}

The students were asked nine questions which demanded answers "yes" or "no" only. In four questions, there were more respondents who answered "yes" than those who said "no" to the various aspects regarding mathematics. The summary showing these responses is shown in Table 4. 
Table 3. ANOVA.

\begin{tabular}{|c|c|c|c|c|c|c|}
\hline \multicolumn{7}{|c|}{ ANOVA } \\
\hline & & $\begin{array}{l}\text { Sum of } \\
\text { Squares }\end{array}$ & df & $\begin{array}{l}\text { Mean } \\
\text { Square }\end{array}$ & $\mathrm{F}$ & Sig. \\
\hline \multirow{3}{*}{ Fear } & Between Groups & 7.166 & 1 & 7.166 & 3.961 & 0.048 \\
\hline & Within Groups & 455.858 & 252 & 1.809 & & $(p<0.05)$ \\
\hline & Total & 463.024 & 253 & & & \\
\hline \multirow{3}{*}{ Uneasy } & Between Groups & 4.553 & 1 & 4.553 & 2.827 & 0.094 \\
\hline & Within Groups & 405.813 & 252 & 1.610 & & \\
\hline & Total & 410.366 & 253 & & & \\
\hline \multirow{3}{*}{$\begin{array}{l}\text { I am afraid to question } \\
\text { when math is involved }\end{array}$} & Between Groups & 2.487 & 1 & 2.487 & 1.244 & 0.266 \\
\hline & Within Groups & 503.938 & 252 & 2.000 & & \\
\hline & Total & 506.425 & 253 & & & \\
\hline \multirow{3}{*}{$\begin{array}{l}\text { I get worried with } \\
\text { difficult calculations }\end{array}$} & Between Groups & 13.910 & 1 & 13.910 & 7.020 & 0.009 \\
\hline & Within Groups & 499.354 & 252 & 1.982 & & $(p<0.01)$ \\
\hline & Total & 513.264 & 253 & & & \\
\hline \multirow{3}{*}{$\begin{array}{l}\text { I do not want } \\
\text { math in my modules }\end{array}$} & Between Groups & 21.610 & 1 & 21.610 & 10.244 & 0.002 \\
\hline & Within Groups & 531.571 & 252 & 2.109 & & $(p<0.05)$ \\
\hline & Total & 553.181 & 253 & & & \\
\hline \multirow{3}{*}{ I avoid math at the earliest } & Between Groups & 13.481 & 1 & 13.481 & 5.873 & 0.016 \\
\hline & Within Groups & 578.397 & 252 & 2.295 & & $(p<0.05)$ \\
\hline & Total & 591.878 & 253 & & & \\
\hline \multirow{3}{*}{$\begin{array}{l}\text { I feel an increased heart } \\
\text { beat when doing math }\end{array}$} & Between Groups & 0.752 & 1 & 0.752 & 0.407 & 0.524 \\
\hline & Within Groups & 465.976 & 252 & 1.849 & & \\
\hline & Total & 466.728 & 253 & & & \\
\hline \multirow{3}{*}{ I do not want calculations } & Between Groups & 3.277 & 1 & 3.277 & 1.520 & 0.219 \\
\hline & Within Groups & 543.400 & 252 & 2.156 & & \\
\hline & Total & 546.677 & 253 & & & \\
\hline \multirow{3}{*}{ I do not like math ever } & Between Groups & 6.957 & 1 & 6.957 & 0.878 & 0.350 \\
\hline & Within Groups & 1995.878 & 252 & 7.920 & & \\
\hline & Total & 2002.835 & 253 & & & \\
\hline \multirow{3}{*}{ I do not like math } & Between Groups & 0.289 & 1 & 0.289 & 0.136 & 0.713 \\
\hline & Within Groups & 536.943 & 252 & 2.131 & & \\
\hline & Total & 537.232 & 253 & & & \\
\hline \multirow{3}{*}{$\begin{array}{l}\text { I am not comfortable } \\
\text { with Math }\end{array}$} & Between Groups & 3.546 & 1 & 3.546 & 1.690 & 0.195 \\
\hline & Within Groups & 528.883 & 252 & 2.099 & & \\
\hline & Total & 532.429 & 253 & & & \\
\hline \multirow{3}{*}{ I have a mind block } & Between Groups & 4.452 & 1 & 4.452 & 2.370 & 0.125 \\
\hline & Within Groups & 473.410 & 252 & 1.879 & & \\
\hline & Total & 477.862 & 253 & & & \\
\hline \multirow{3}{*}{ I sweat } & Between Groups & 0.396 & 1 & 0.396 & 0.213 & 0.645 \\
\hline & Within Groups & 468.159 & 252 & 1.858 & & \\
\hline & Total & 468.555 & 253 & & & \\
\hline \multirow{3}{*}{ I get bored } & Between Groups & 1.492 & 1 & 1.492 & 0.767 & 0.382 \\
\hline & Within Groups & 489.977 & 252 & 1.944 & & \\
\hline & Total & 491.469 & 253 & & & \\
\hline
\end{tabular}


Table 4. More answered "yes" than "no".

\begin{tabular}{lccc}
\hline \multicolumn{1}{c}{ Question } & Yes & No & Difference \\
\hline Do you feel uneasy when performing mathematics calculations? & 145 & 87 & 58 \\
Do you fear asking questions while attending a mathematics class? & 122 & 110 & 12 \\
Do you like mathematics in general? & 126 & 106 & 20 \\
Do you sweat when performing mathematics calculations? & 122 & 110 & 12
\end{tabular}

In respect of the other five questions, more respondents indicated "no" than those who said "yes" to the questions asked. This is depicted in Table 5.

\section{Inferential Statistics}

\section{Chi-Square Test}

The Chi Square Goodness of Fit Test analyses are applied when we are working with nominal variables, specifically; the possible values for the variables are categorical and cannot be ranked. In this study, the categorical values are "yes" and "no". The requirements for the test were adequately met as follows:

- The sample was randomly drawn from the population. The population comprised all the students at BA ISAGO University while a sample of 232 students was randomly selected.

- The values of the categorical variables were mutually exclusive-the questions needed either a "yes" or a "no" only.

- There was a minimum expectation of five occurrences in each category.

The Null hypothesis specifies the expected frequency for each category. We interviewed 232 students and for each question, we expected that half of the students would say "yes" while the other half would say "no". In this regard, the null hypothesis was:

$H_{a}$ : There was no difference in the students who answer "yes" or "no" to any of the questions asked. In other words, there was an equal distribution.

The research hypothesis (the alternative hypothesis) was:

$H_{b}$ : There was a difference between students who answered "yes" and those who said "no" to any of the research questions. In other words, there was an unequal distribution between those who agreed and those who disagreed.

For instance, of the two hundred and thirty-two (232) students sampled and evaluated as to whether the number who feared math $(f=92)$ was equal to the number who did not fear math $(f=140)$, the Null hypothesis was rejected:

$x^{2}(1)=9.931, p \leq 0.05$. Ninety-two (92) students feared math while one hundred and forty (140) did not fear the subject.

The rest of the analyses are summarized in Table 6.

\section{Discussion}

This study aimed at investigating whether there was any difference in how math anxiety affects male and female students at BA ISAGO University.

The results obtained concluded that there were statistically significant differences between the means for male and female students in respect of, sweating in 
Table 5. More answered "no" than "yes".

\begin{tabular}{|c|c|c|c|}
\hline Question & Yes & No & Difference \\
\hline Do you fear mathematics? & 92 & 140 & 48 \\
\hline Do you get worried when performing math calculations? & 83 & 149 & 66 \\
\hline Do you like mathematics modules in your programme? & 114 & 118 & 4 \\
\hline $\begin{array}{l}\text { Do you experience a mind block when performing } \\
\text { mathematics calculations? }\end{array}$ & 85 & 147 & 62 \\
\hline Do you get bored when performing mathematics calculations? & 68 & 164 & 96 \\
\hline
\end{tabular}

Table 6. Results of chi-square goodness of fit tests.

\begin{tabular}{|c|c|c|c|c|c|}
\hline \multirow{2}{*}{$\#$} & \multirow{2}{*}{ Question } & \multicolumn{2}{|c|}{ How many said } & \multirow{2}{*}{ Test Statistic } & \multirow{2}{*}{ Reject/Retain? } \\
\hline & & Yes? & No? & & \\
\hline 1 & Do you fear mathematics? & 92 & 140 & $x^{2}(1)=9.931, p \leq 0.05$ & Reject Null \\
\hline 2 & $\begin{array}{l}\text { Do you feel uneasy when } \\
\text { performing mathematics } \\
\text { calculations? }\end{array}$ & 145 & 87 & $x^{2}(1)=14.500, p \leq 0.05$ & Reject Null \\
\hline 3 & $\begin{array}{l}\text { Do you fear asking } \\
\text { questions while attending } \\
\text { a mathematics class? }\end{array}$ & 122 & 110 & $x^{2}(1)=0.621, p \geq 0.05$ & Retain Null \\
\hline 4 & $\begin{array}{l}\text { Do you get worried } \\
\text { when performing } \\
\text { math calculations? }\end{array}$ & 83 & 149 & $x^{2}(1)=18.776, p \leq 0.05$ & Reject Null \\
\hline 5 & $\begin{array}{l}\text { Do you like } \\
\text { mathematics modules } \\
\text { in your programme? }\end{array}$ & 114 & 118 & $x^{2}(1)=0.069, p \geq 0.05$ & Retain Null \\
\hline 6 & $\begin{array}{l}\text { Do you like } \\
\text { mathematics in general? }\end{array}$ & 126 & 106 & $x^{2}(1)=1.724, p \geq 0.05$ & Retain Null \\
\hline 7 & $\begin{array}{l}\text { Do you experience a mind } \\
\text { block when performing } \\
\text { mathematics calculations? }\end{array}$ & 85 & 147 & $x^{2}(1)=16.569, p \leq 0.05$ & Reject Null \\
\hline 8 & $\begin{array}{l}\text { Do you sweat when } \\
\text { performing mathematics } \\
\text { calculations? }\end{array}$ & 122 & 110 & $x^{2}(1)=0.621, p \geq 0.05$ & Retain Null \\
\hline 9 & $\begin{array}{l}\text { Do you get bored } \\
\text { when performing } \\
\text { mathematics calculations? }\end{array}$ & 68 & 164 & $x^{2}(1)=39.724, p \leq 0.05$ & Reject Null \\
\hline
\end{tabular}

the palms (Henrich \& Lee, 2011; Pourmoslemi et al., 2013), fear of, worry for and avoidance of, a feeling of uneasiness for, having a mind block in, boredom with and dislike of mathematics. These constructs have been extensively studied and documented by Keshavarzi and Ahmadi (2013) who expressed concern over the possible extinction of human resources in science and technology if the math anxiety problem is not contained. Perhaps, as a way to go to the bottom of the math anxiety phenomenon, Murat (2009) then suggested the possibility of testing the teachers for math anxiety. Murat's argument signifies the notion that 
math anxiety may not only in the students but can also be inherent in the teachers themselves. Hlalele (2012) concluded that mathematics anxiety had negative effects on confidence, motivation and math achievement.

In spite of the fact that it has widely been studied, mathematics anxiety has continued to negatively affect mathematics learning and teaching. The findings of the study indicated that male and female students differ in their perception in respect of fear for and worry about mathematics leading to total avoidance all together. The study further showed that students generally fear mathematics, experience a mind block and get bored when faced with math exercises. Again, students indicated that they feared asking questions during a math lesson, hated math modules in their degree, sweated and disliked math altogether.

Particularly, statistically significant differences between the means for male and female students regarding some aspects of math were evident. Pourmoslemi et al.'s (2013) study showed that there existed differences between men and women's evaluation anxiety although no significant difference was observed concerning the field of study. Karimi \& Venkatesan (2009) used the term boys and girls in reaching the same conclusion. Additionally, Shiraz, Keshavarzi and Ahmadi (2013) discovered that males and females were equally affected by the phenomenon. Using multiple regression analysis, Ayotola and Adedeji (2009) found out that mathematics self-efficacy, gender and anxiety had significant correlations with students' achievement in mathematics. Yet Yeo, Tan and Lew (2015) found no significant difference of anxiety among the male and female students at a private University.

\section{Conclusion}

This study attempted to investigate whether there was any gender based statistically significant difference in math anxiety at BA ISAGO University. This kind of study is not conclusive and requires a much bigger insight into the problem on a national scale. They are only discovered by a keen teacher who closely monitors students' progress, successes and failures. The rest continually suffers in silence. The study used a questionnaire to collect math anxiety data based on students' reactions towards mathematics. The study used descriptive, ANOVA and Chi Square statistical analyses. The results obtained for a good basis for further research.

The problem of math anxiety affects, among others, all ages and all groupings within classes or in any other setting. Various strategies are needed to deal with the problem of math anxiety.

\section{Acknowledgements}

Acknowledging the importance of mathematics in humankind in so far as it is applied in all disciplines, a study of this nature is undoubtedly significant to every forum, including, academia, general life and literature review. Murat (2009) also opened this research to test math anxiety in teachers, a significant implication of research that has unfolded so far. 


\section{Conflicts of Interest}

The authors declare no conflicts of interest regarding the publication of this paper.

\section{References}

Ayotola, A., \& Adedeji, T. (2009). The Relationship between Gender, Age, Mental Ability, Anxiety, Mathematics Self-Efficacy and Achievement in Mathematics. Cypriot Journal of Educational Sciences, 4, 113-124.

Ballado, R. S. (2014). Mathematics Anxiety and Academic Achievement of Junior Pre-Service Teacher Education Students. In The 2014 WEI International Academic Conference Proceedings (p. 224). Kitwe: The West East Institute.

Chowdhury, M., Paul, H., \& Das, A. (2007). The Impact of Top Management Commitment on Total Quality Management Practice: An Exploratory Study in the Thai Garment Industry. Global Journal of Flexible Systems Management, 8, 17-29. https://doi.org/10.1007/BF03396517

Erdogan, A., Kesici, S., \& Şahin, I. (2011). Prediction of High School Students' Mathematics Anxiety by Their Achievement Motivation and Social Comparison. Elementary Education Online, 10, 646-652.

Henrich, A., \& Lee, K. (2011). Reducing Mathematics Anxiety: Findings from Incorporating Service Learning into a Quantitative Reasoning Course at Seattle University. Advancing Education in Quantitative Literacy, 4, Article No. 9. https://doi.org/10.5038/1936-4660.4.2.9

Hlalele, D. (2012). Exploring Rural High School Learners' Experience of Mathematics Anxiety in Academic Settings. South African Journal of Education, 32, 267-278. https://doi.org/10.15700/saje.v32n3a623

Ho, H., Senturk, D., Lam, A. G., Zimmer, J. M., Hong, S., Nakazawa, Y. O. S. C. Y., \& Wang, C. (2000). The Affective and Cognitive Dimensions of Math Anxiety: A Cross-National Study. Journal for Research in Mathematics Education, 31, 362-379. https://doi.org/10.2307/749811

Hung, R. Y., Lien, B. Y., Fang, S., \& McLean, G. N. (2010). Knowledge as a Facilitator for Enhancing Innovation Performance through Total Quality Management. Total Quality Management, 21, 425-438. https://doi.org/10.1080/14783361003606795

Karimi, A., \& Venkatesan, S. (2009). Cognitive Behaviour Group Therapy in Mathematics Anxiety. Journal of the Indian Academy of Applied Psychology, 135, 299-303.

Keshavarzi, A., \& Ahmadi, S. (2013). A Comparison of Mathematics Anxiety among Students by Gender. Procedia-Social and Behavioral Sciences, 83, 542-546. https://doi.org/10.1016/j.sbspro.2013.06.103

Kuo, T., Chang, T., Hung, K., \& Lin, M. (2009). Employees' Perspective on the Effectiveness of the ISO 9000 Certification: A Total Quality Management Framework. Total Quality Management, 20, 1321-1335. https://doi.org/10.1080/14783360903250530

Maloney, E. A., Ansari, D., \& Fugelsang, J. A. I2011). Rapid Communication: The Effect of Mathematics Anxiety on the Processing of Numerical Magnitude. The Quarterly Journal of Experimental Psychology, 64, 10-16. https://doi.org/10.1080/17470218.2010.533278

Murat, P. (2009). Pre-Service Teachers' Teaching Anxiety about Mathematics and Their Learning Styles. Eurasia Journal of Mathematics, Science \& Technology Education, 5, 335-345. https://doi.org/10.12973/ejmste/75284 
Pourmoslemi, A., Erfani, N., \& Firoozfar, I. (2013). Mathematics Anxiety, Mathematics Performance and Gender Differences among Undergraduate Students. International Journal of Scientific and Research Publications, 3, 1-6. http://www.ijsrp.org

Sakthivel, P. B., \& Raju, R. (2006). Conceptualizing Total Quality Management in Engineering Education and Developing a TQM Educational Excellence Model. Total Quality Management, 17, 913-934. https://doi.org/10.1080/14783360600595476

Thomas, R. (1998). A Comparison between Male and Female Mathematics Anxiety at a Community College. Master's Thesis, New Britain, CT: Central Connecticut State University.

Whyte, J., \& Anthony, G. (2012). Math's Anxiety: The Fear Factor in the Mathematics Classroom. New Zealand Journal of Teachers' Work, 9, 6-15.

Yeo, W. L., Tan, C. K., \& Lew, S. L. (2015). Mathematics Anxiety among Male and Female Students. International Journal of Social, Behavioral, Educational, Economic, Business and Industrial Engineering, 9, 2830-2835.

Zadry, H. R., \& Yusof, A. M. (2006). Total Quality Management and Theory of Constraints Implementation in Malaysian Automotive Suppliers: A Survey Result. Total Quality Management, 17, 999-1020. https://doi.org/10.1080/14783360600747911 